\title{
Kekeringan Meteorologis dengan Metode Thornthwaite-Mather di DAS Sembung, Kabupaten Sleman, DIY
}

\author{
${ }^{1}$ Afid Nurkholis, ${ }^{1}$ Yuli Widyaningsih, ${ }^{1}$ Ayu Dyah Rahma, ${ }^{1}$ Amalya Suci, ${ }^{1}$ Ardian Abdillah, ${ }^{1}$ Gina Aprila \\ Wangge, ${ }^{1}$ Arum Sari Widiastuti, ${ }^{1}$ Deka Ayu Maretya \\ ${ }^{1}$ Departemen Geografi Lingkungan, Fakultas Geografi, Universitas Gadjah Mada \\ email author: afidnurkholis@gmail.com
}

\begin{abstract}
Abstrak
Kekeringan secara sederhana dapat diartikan sebagai kurangnya kebutuhan air bagi kehidupan makhluk hidup di suatu wilayah. Kekeringan dapat diklasifikasn menjadi empat jenis, yaitu : kekeringan meteorologis, hidrologis, pertanian, dan sosial-ekonomi. Jenis kekeringan tersebut merupakan suatu tingkatan dimana kekeringan paling awal yang terjadi adalah meteorologis hingga yang paling parah adalah sosial-ekonomi. DAS Sembung di Kabupaten Sleman merupakan wilayah yang saat ini mengalami pembangunan. Penggunaan lahan permukiman mulai didirikan mengganti lahan pertanian. Analisis kekeringan perlu dilakukan agar mitigasi dan ancaman kekurangan air dapat diprediksi dan dilakukan mitigasi. Pengukuran kekeringan meteorologis dilakukan dengan menggukana metode Thornthwaite-Mather. Parameter yang digunakan adalah Indeks moisture (Im), Indeks humidity (Im), dan Indeks aridity (Ia). Hasil penelitian menunjukkan bahwa Index Moisture di Lereng Kaki Volkan yaitu kelas A-Perhumid di Desa Pakembinangun, kelas B4 di Desa Umbulmartani, B3 di Desa Sardonoharjo. Wilayah Dataran Kaki Volkan dan Teras Sungai Index moisture didominasi oleh B3-Humid. Index Aridity di seluruh DAS Sembung termasuk kelas $S$ yaitu defisiensi air pada musim panas sedang. Index Humidity di seluruh DAS Sembung memiliki kelas $S 2$ yaitu Surplus air pada musim kemarau panjang.
\end{abstract}

kata kunci: kekeringan meteorologis, Indeks humidity, Indeks moisture, Indeks aridity, DAS Sembung, Kabupaten Sleman, Thornthwaite-Mather

\section{Sitasi model APA}

Nurkholis, A., Widyaningsih, Y., Rahma, A. D., Suci, A., Abdillah, A., Wangge, G. A., Widiastuti, A. S., Maretya, D. A. (2016, March 30). Kekeringan Meteorologis dengan Metode Thornthwaite-Mather di DAS Sembung, Kabupaten Sleman, DIY. http://doi.org/10.17605/OSF.IO/NHK5D 


\section{PENDAHULUAN}

Kekeringan secara sederhana dapat diartikan sebagai kurangnya kebutuhan air bagi kehidupan makhluk hidup di suatu wilayah (Soenarto dkk, 2003). Menurut Shelia B. Red (1992), kekeringan adalah pengurangan petersediaan air atau kelembapan secara signifikan di bawah keadaan normal atau volume yang diharapkan untuk jangka waktu khusus yang bersifat sementara. Kekeringan bersifat sementara dalam artian tidak diketahui kapan berawal dan kapan berakhir. Selain itu, kekeringan juga merupakan bencana yang kompleks sehingga melibatkan banyak pihak (Soenarto dkk, 2003).

Kekeringan merupakan salah satu permasalahan dunia saat ini . Kejadian ini telah mengalami peningkatan signifikan di beberapa wilayah salah satunya adalah Tiongkok. Menurut IPCC (2012), jumlah area yang terkena dampak kekeringan di dunia akan meningkat $15-44 \%$ dari sekarang hingga akhir abad 21. Sementara itu, Tiongkok mengalami peningkatan rata-rata tahunan lahan pertanian yang terkena kekeringan dari 11.6 juta hektar pada tahuan 1950-an menjadi 25.1 juta hektar pada awal abad 21. Peningkatan tersebut jika dipersenkan adalah senilai $116 \%$.

Kekeringan dapat diklasifikasn menjadi empat jenis menurut Shelia B. Red (1995), yaitu : kekeringan meteorologis, hidrologis, pertanian, dan sosial-ekonomi. Jenis kekeringan tersebut merupakan suatu tingkatan dimana kekeringan paling awal yang terjadi adalah meteorologis hingga yang paling parah adalah sosial-ekonomi. Salah satu kekeringan yang terjadi di Tiongkok masuk ke tahap kekeringan pertanian hingga sosial-ekonomi. Kekeringan meteorologis akibat perubahan iklim menyebabkan pola curah hujan berubah. Keterbatasan ketersediaan air tersebut membuat lahan pertanian kekurangan pasokan air untuk bertani akibatnya adalah terjadi kekeringan pertanian. Kondisi tersebut memicu menurunya produktifitas pangan dan penghasilan para petani sehingga dapat disebut sebagai kekeringan sosial-ekonomi.

DAS Sembung di Kabupaten Sleman merupakan wilayah yang saat ini mengalami pembangunan (Wangge dkk, 2016). Penggunaan lahan permukiman mulai didirikan mengganti lahan pertanian. Pembangunan tersebut perlu memperhatikan aspek ketersediaan dan kebutuhan air (Nurkholis dkk, 2016). Selain itu, analisis kekeringan perlu dilakukan agar mitigasi dan ancaman kekurangan air dapat diprediksi dan dilakukan mitigasi.

\section{WILAYAH KAJIAN}

DAS Sembung merupakan bagian dari DAS Opak. DAS Sembung dibagi menjadi tiga zonasi yaitu hulu, tengah, dan hilir. Penutup lahan yang dominan di DAS Sembung yaitu sebagai pertanian, perkebunan, dan permukiman. Klasifikasi lereng di DAS Sembung berupa lereng yag datar dan landai. Formasi batuan yang terdapat pada DAS Sembung berupa Qmi/ Qvu3 yaitu Endapan Volkanik Merapi Muda yang terdiri dari tuff, abu, breksi, aglomerat, dan leleran lava tak terpisahkan. Formasi ini berhulu pada Gunungapi Merapi dan menyusun sebagian besar lereng 
Gunung Merapi. Formasi berumur kuarter dan masih terus mengalami proses erupsi. Material yang tersusun merupakan hasil dari akumulasi erupsi Gunung Merapi. DAS Sembung memiliki tiga bentuklahan, yaitu lereng kaki volkanik, dataran kaki volkanik, dan teras sungai (Gambar 2.1).

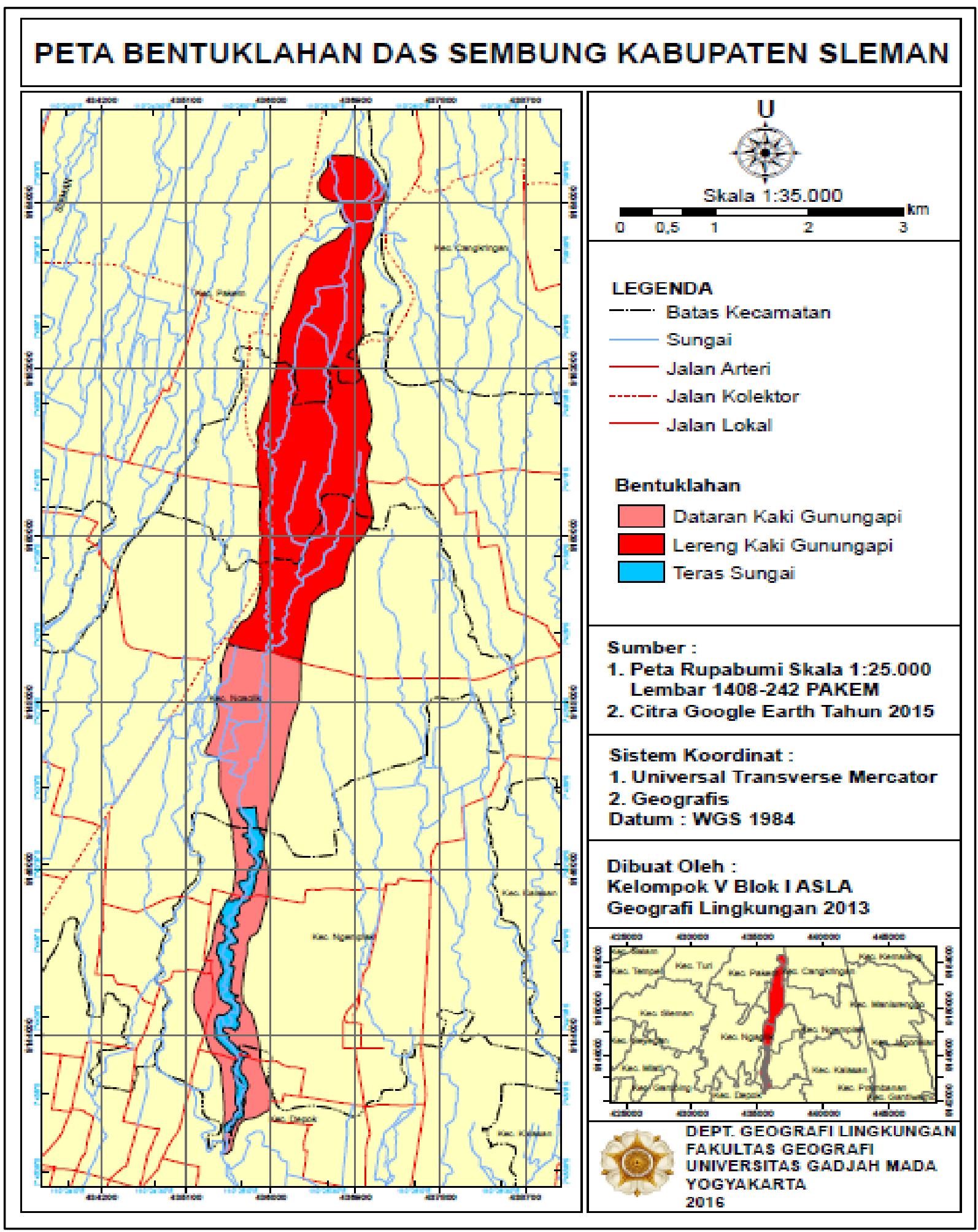

Gambar 2.1. Peta Bentuklahan DAS Sembung 


\section{METODE PENELITIAN}

Penilaian terhadap kekeringan di DAS Sembung ditunjukkan dengan indeks kekeringan berdasarkan metode Thornthwaite-Mather (1957). Metode ini berdasarkan dengan imbangan air yang ditunjukkan dengan nilai Indeks Moisture (Im), Indeks Aridity (Ia), Indeks Humidity (Ih) (Gambar 3.1).

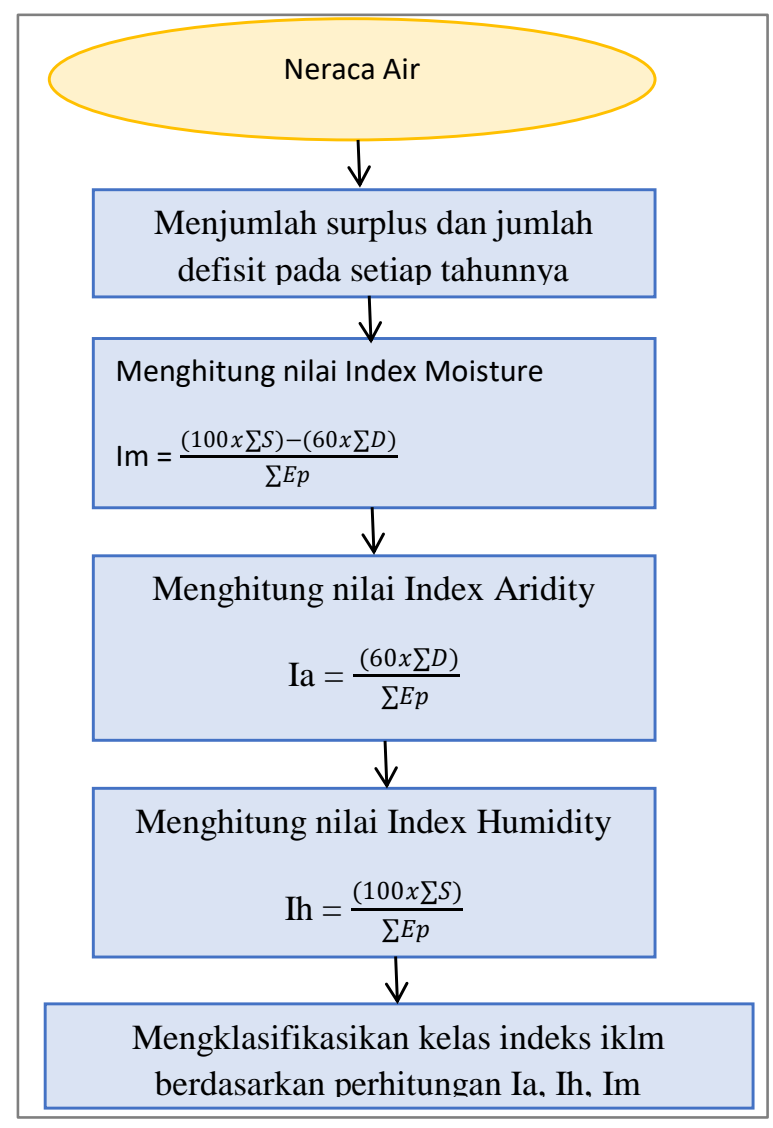

Gambar 3.1. Perhitungan indeks kekeringan metode Thornthwaite-Mather

Im dicari dengan persamaan (1) sebagai berikut:

$\operatorname{Im}=\frac{\left(100 x \sum S\right)-\left(60 x \sum D\right)}{\Sigma E p}$

$\operatorname{Im}=$ Indeks Lengas

$$
\begin{aligned}
& \mathrm{D}=\text { Defisit Lengas } \\
& \mathrm{Ep}=\text { Evapotranspirasi potensial }
\end{aligned}
$$

$\mathrm{S}=$ Surplus

Kriteria untuk Im disajikan pada Tabel 3.1. Sementara itu, klasifikasi iklim berdasarkan Im ditunjukkan pada Tabel 3.2.

Tabel 3.1. Kriteria Indek moisture (Im)

\begin{tabular}{|l|l|}
\hline \multicolumn{1}{|c|}{ Kriteria } & \multicolumn{1}{c|}{ Ciri } \\
\hline Neither dry or humid & $\mathrm{Im}=0$ \\
\hline Humid & $\mathrm{Im}>0$ \\
& $\mathrm{~S}>0,6 \mathrm{D}$ \\
\hline Dry & $\mathrm{Im}<0$ \\
& $\mathrm{~S}<0,6 \mathrm{D}$ \\
\hline
\end{tabular}


Tabel 3.2. Klasifikasi Iklim berdasarkan Indeks moisture (Im)

\begin{tabular}{|l|l|l|}
\hline Moisture Province & Vegetasi & Index moisture \\
\hline A - Perhumid & Hutan yang rapat & $>100$ \\
\hline $\mathrm{B}_{1}-$ Humid & Hutan & $80-100$ \\
\hline $\mathrm{B}_{2}-$ Humid & Hutan & $60-80$ \\
\hline $\mathrm{B}_{3}-$ Humid & Hutan & $40-20$ \\
\hline $\mathrm{B}_{4}-$ Humid & Humid & $20-40$ \\
\hline $\mathrm{C}_{1}-$ Moist Sub - Humid & Padang rumput yang tinggi & $0-20$ \\
\hline $\mathrm{C}_{2}-$ Dry Sub - Humid & Rumput rendah & $(-20)-0$ \\
\hline $\mathrm{D}_{1}-$ Semi Arid & Stepa & $(-40)-(-20)$ \\
\hline $\mathrm{D}_{2}-$ Arid & Gurun & $(-60)-(-40$ \\
\hline
\end{tabular}

Perhitungan Indeks humidity (Ih) dan Indeks aridity (Ia) dijelaskan oleh persamaan (2) dan (3).

$\mathrm{Ih}=\frac{100 * \sum S}{\sum E p}$
$\mathrm{Ia}=\frac{100 * \sum D}{\sum E p}$

Dimana Ep adalah evapotranspirasi potensial, S adalah surplus, dan D adalah defisit. Klasifikasi Ih ditunjukkan oleh Tabel 3.3 sedangkan Ia pada Tabel 3.4

Tabel 3.3. Klasifikasi Indeks humidity (Ih)

\begin{tabular}{|l|l|l|}
\hline Sub Devisi & \multicolumn{1}{|c|}{ Keterangan } & Index Aridity \\
\hline $\mathrm{R}$ & Sedikit atau tidak ada surplus air & $0-10$ \\
\hline $\mathrm{S}$ & Defisiensi air pada musim panas sedang & $10-20$ \\
\hline $\mathrm{W}$ & Defisiensi air pada musim dingin & $10-20$ \\
\hline $\mathrm{S}_{2}$ & Surplus air pada musim panas besar & $>20$ \\
\hline $\mathrm{W}_{2}$ & Surplus air pada musim dingin besar & $>20$ \\
\hline
\end{tabular}

Tabel 3.4. Klasifikasi Indeks aridity (Ia)

\begin{tabular}{|l|l|l|}
\hline Sub Devisi & \multicolumn{1}{|c|}{ Keterangan } & Index Aridity \\
\hline $\mathrm{R}$ & Sedikit atau tidak ada defisiensi air & $0-6,7$ \\
\hline $\mathrm{S}$ & Defisiensi air pada musim panas sedang & $16,7-33,3$ \\
\hline $\mathrm{W}$ & Defisiensi air pada musim dingin & $16,7-33,3$ \\
\hline $\mathrm{S}_{2}$ & Defisiensi air pada musim panas besar & $>33,3$ \\
\hline $\mathrm{W}_{2}$ & Defisiensi air pada musim dingin besar & $>33,3$ \\
\hline
\end{tabular}

\section{HASIL DAN PEMBAHASAN}

Indeks Kekeringan pada desa-desa di DAS Sembung ditunjukkan oleh Index aridity, Indeks humidity dan Index moisture. Metode yang digunakan dalam perhitungan yaitu metode Thornthwaite Mather. Metode ini menggunakan model imbangan air yang mengguakan variabel curah hujan, koefisien evapotranspirasi, runoff dan ketersediaan lengas tanah. Berdasarkan hasil perhitungan menggunakan Metode Thornthwaite Mather yang menggunakan konsep imbangan air atau neraca air diperoleh hasil per desa dalam setiap bentuklahan (Tabel 4.1). 
Tabel 4.1. Hasil perhitungan indeks kekeringan di DAS Sembung

\begin{tabular}{|c|c|c|c|c|c|c|c|c|c|c|}
\hline \multirow{2}{*}{ BL } & \multirow{2}{*}{ Desa } & \multicolumn{3}{|c|}{ Data } & \multicolumn{3}{|c|}{ Kekeringan } & \multicolumn{3}{|c|}{ Kelas Kekeringan } \\
\hline & & Ep & $\mathbf{s}$ & D & Im & la & Ih & Im & la & Ih \\
\hline \multirow{4}{*}{$\begin{array}{l}\text { Lereng Kaki } \\
\text { Gunungapi }\end{array}$} & $\begin{array}{l}\text { Pakem } \\
\text { Binangun }\end{array}$ & 1152,38 & 1417,36 & 248,00 & 110,08 & 21,52 & 122,99 & A-Perhumid & $\mathrm{s}$ & S2 \\
\hline & Umbulmartani & 1152,38 & 1193,07 & 248,13 & 90,61 & 21,53 & 103,53 & B4-Humid & $\mathrm{s}$ & S2 \\
\hline & Sardonoharjo & 1169,52 & 1031,24 & 279,88 & 73,82 & 23,93 & 88,18 & B3-Humid & $\mathrm{s}$ & $\mathrm{S} 2$ \\
\hline & Suko Harjo & 1157,78 & 729,46 & 301,36 & 47,39 & 26,03 & 63,01 & B2-Humid & $\mathrm{s}$ & S2 \\
\hline \multirow{6}{*}{$\begin{array}{c}\text { Dataran } \\
\text { Kaki } \\
\text { Gunungapi }\end{array}$} & Wedomartani & 1223,21 & 930,59 & 297,24 & 61,50 & 24,30 & 76,08 & B3-Humid & $\mathrm{s}$ & S2 \\
\hline & Sardonoharjo & 1187,88 & 996,60 & 290,93 & 69,20 & 24,49 & 83,90 & B3-Humid & $\mathrm{s}$ & $\mathrm{S} 2$ \\
\hline & Suko Harjo & 1199,46 & 983,57 & 288,41 & 67,57 & 24,05 & 82,00 & B3-Humid & $\mathrm{s}$ & S2 \\
\hline & Sinduharjo & 1204,69 & 954,46 & 297,39 & 64,42 & 24,69 & 79,23 & B3-Humid & $\mathrm{s}$ & S2 \\
\hline & Condong Catur & 1262,18 & 904,15 & 313,16 & 56,75 & 24,81 & 71,63 & B2-Humid & $\mathrm{s}$ & S2 \\
\hline & Maguwoharjo & 1252,62 & 945,31 & 309,07 & 60,66 & 24,67 & 75,47 & B3-Humid & $\mathrm{s}$ & S2 \\
\hline \multirow{3}{*}{$\begin{array}{l}\text { Teras } \\
\text { Sungai }\end{array}$} & Wedomartani & 1221,41 & 933,15 & 298,44 & 61,74 & 24,43 & 76,40 & B3-Humid & $\mathrm{s}$ & S2 \\
\hline & Sinduharjo & 1209,90 & 949,76 & 299,00 & 63,67 & 24,71 & 78,50 & B3-Humid & $\mathrm{s}$ & S2 \\
\hline & Maguwoharjo & 1234,53 & 928,72 & 311,58 & 60,09 & 25,24 & 75,23 & B3-Humid & $\mathrm{S}$ & $\mathrm{S} 2$ \\
\hline
\end{tabular}

Berdasarkan hasil perhitungan yang dilakukan Index moisture (Im), DAS Sembung didominasi oleh kelas Humid dengan variasi yang beragam. Wilayah yang paling basah di DAS Sembung dijumpai di Desa Pakembinangun yang menunjukkan kelas A-Perhumid. Wilayah dengan kelas A-Perhumid biasanya memiliki jenis penggunaan lahan hutan rapat atau tumbuhan tingkat tingggi. Hal ini dikarenakan wilayah ini termasuk zona basah yang memiliki curah hujan tinggi. Berdasarkan hujan wilayah isohyet di wilayah lereng kaki terutama di Desa Pakembinangun dan Umbulmartani memiliki curah hujan rerata bulan basah mencapai $417 \mathrm{~mm}$ pada bulan Januari. Hal ini dapat disebabkan oleh kondisi geografis dari Desa Pakembinangun yang mendapatkan pengaruh dari hujan orografis.

Desa Umbulmartani yang berada di Lereng Kaki Volkan yang memiliki kelas Index moisture B4 - Humid. Desa Umbulmartani yang memiliki morfologi sama masih terpengaruh oleh hujan orografis dimana pada bulan basah curah hujan rerata mampu mencapai $382,8 \mathrm{~mm}$. Berdasarkan kelas B4 - Humid vegetasi yang dapat tumbuh adalah vegetasi tingkat tinggi, atau penggunaan lahan berupa hutan. Kelas B3 - Humid merupakan kelas dimana hutan mampu berkemng pada wilayah ini. Wilayah di DAS Sembung didominasi oleh kelas Index moisture B3 - Humid. Desa-desa yang termasuk ke dalam kelas ini yaitu Sardonoharjo, sebagian Sukoharjo pada Dataran Kaki Volkan, Sinduharjo, Wedomartani, dan Maguwoharjo. Desa Condongcatur dan Sukoharjo di bagian Lereng Kaki Volkan termasuk ke dalam kelas B2 - Humid. 
DAS Sembung memiliki Index Aridity masuk ke dalam kelas S defisiensi air pada musim panas sedang. Wilayah DAS Sembung yang masuk ke dalam iklim tropis mengalami dua musim secara makro yaitu musim penghujan dan usim kemarau. Index Aridity menunjukkan defisit ketersediaan air pada DAS Sembung memiliki tingkat sedang. Semua desa masuk ke dalam kelas ini. Hal ini menunjukkan kondisi yang seragam dalam satu sistem DAS. Tingkat defisiensi air pada musim panas atau kemarau ini dapat dilihat potensi ketersediaan air di DAS Sembung. Oleh karenanya perlu pengelolaan air terpadu agar tidak terjadi defisit air pada musim kemarau. Adanya

Embung Tambakbayan di bagian hilir DAS menjadi salah satu alternati untuk menampung runoff saat terjadi hujan. Hal ini berguna sebagi tempat penampungan air agar tidak mengalir siasia. Pengelolaan Embung Tambakbayan haruslah menjadi salah satu alternatif untuk mengatasi defisiensi air terutama untuk kebutuhan irigasi pada musim kemarau. Alternatif lainnya dapat dibangun saluran-saluran irigasi yang terencana untuk menampung air dan mengairi lahan pertanian.

Berdasarkan perhitungan Index Humidity seluruh wilayah DAS Sembung termasuk ke dalam kelas Ih S2 yang berarti surplus air pada musim panas atau kemarau besar. Berdasarkan neraca ai surplus ditunjukkan dengan nilai runoff yang tinggi. Surplus dalam neraca air telah termasuk air pada permukaan dan airtanah.Defisit yang terjadi paa musim kemarau dapat disebabkan oleh proses evapotranspirasi yang tinggi sehingga hasil surplus berkurang akibat adanya eapotranspirasi. Evapotranspirasi pada musim kemarau dapat menyebabkan penyusutan debit sungai. Hal ini mampu mneyebabkan adanya defisiensi air pada musim kemarau

\section{KESIMPULAN}

Index Moisture di Lereng Kaki Volkan yaitu kelas A-Perhumid di Desa Pakembinangun, kelas B4 di Desa Umbulmartani, B3 di Desa Sardonoharjo. Wilayah Dataran Kaki Volkan dan Teras Sungai Index moisture didominasi oleh B3-Humid. Index Aridity di seluruh DAS Sembung termasuk kelas $S$ yaitu defisiensi air pada musim panas sedang. Index Humidity di seluruh DAS Sembung memiliki kelas S2 yaitu Surplus air pada musim kemarau panjang. 


\section{DAFTAR PUSTAKA}

Goenadi, Soenarto dkk. 2003. Konservasi lahan Terpadu Daerah Rawan Bencana Longsoran Di Kabupaten Kulonprogo Daerah Istemawa Yogyakarta. Laporan Penelitian. Yogyakarta : Pusat Studi Bencana, Universitas Gadjah Mada.

IPCC. 2012. Managing the Risks of Extreme Events and Disasters to Advance Climate Change Adaptation. A Special Report of Working Groups I and II of the Intergovernmental Panel on Climate Change Field, C.B., V.Barros, T.F. Stocker, D. Qin, D.J. Dokken, K.L. Ebi, M.D. Mastrandrea, K.J. Mach,G.-K. Plattner, S.K. Allen, M. Tignor, and P.M. Midgley (eds.)]. Cambridge University Press, Cambridge, United Kingdom and New York, NY, USA, 582pp.

Nurkholis, A., Widyaningsih, Y., Rahma, A. D., Suci, A., Abdillah, A., Wangge, G. A., Widiastuti, A. S., Maretya, D. A. (2016, March 30). Analisis Neraca Air DAS Sembung, Kabupaten Sleman, DIY (Ketersediaan Air, Kebutuhan Air, Kekritisan Air). http://doi.org/10.17605/OSF.IO/YMHKG

Red, Shelia B. 1992. Pengantar Tentang Bahaya. Edisi Ke 3, UNDP dan DMTP.

Thornthwaite, C.W. and Mather, J.R. 1957. Instruction and Table for computing potential evapotranspiration and the water balance. Centerton, N.J. Laboratory of clymatology, Publications in Climatology, v. 10, no. 3, p. 1 - 104.

Wangge, G. A., Widiastuti, A. S., Maretya, D. A., Suci, A., Nurkholis, A., Widyaningsih, Y., Rahma, A. D., Abdillah, A. 2016. Tekanan Penduduk Terhadap Lahan Pertanian di DAS Sembung, Kabupaten Sleman, DIY. http://doi.org/10.17605/OSF.IO/EDAHR 